\title{
USOS DIRECTOS E INDIRECTOS DEL PRESENTE DE INDICATIVO EN LA SEGUNDA MITAD DEL SIGLO XVI*
}

CARlos CUAdRAdo Gómez

UNED

carloscuadradogomez@gmail.com

\section{RESUMEN}

En este artículo estudiamos los usos directos e indirectos del presente de indicativo en la segunda mitad del siglo XVI. A partir del concepto de temporalidad verbal, se analizan todos los presentes que hay en el corpus en el cual se realiza la investigación, valorando y calificando en cada caso el uso que se hace de la forma verbal. Es un estudio de Pragmática Histórica que intenta aportar una nueva orientación y nuevos datos a la historia de la lengua española, en un terreno de la gramática tan delicado como es el sistema verbal.

PALABras Clave: temporalidad verbal, gramática histórica, pragmática, sistema verbal, deixis.

\section{ABSTRACT}

In this article we study the direct and indirect uses of the present of indicative in the second half of the sixteenth century. Based on the concept of tense, we analyze every present that is in the corpus in which the research is conducted, evaluating and qualifying

\footnotetext{
* Este trabajo procede de una investigación más amplia realizada como tesis doctoral por D. Carlos Cuadrado Gómez (2011): La temporalidad verbal en la segunda mitad del siglo XVI. Modo indicativo, UNED, dirigida por la Dra. D. ${ }^{a}$ María Lourdes García-Macho Alonso de Santamaría. La tesis fue defendida el 3 de mayo de 2011, formando parte del tribunal: Dr. D. Antonio Narbona Jiménez (Universidad de Sevilla), Dr. D. José Manuel González Calvo (Universidad de Extremadura), Dra. D. a Teresa Echenique Elizondo (Universidad de Valencia), Dr. D. Manuel Esgueva Martínez (UNED) y Dr. D. Rafael Rodríguez Marín (UNED).
} 
in each case the use made of the verbal form. This article is a study of Historical Pragmatics that attempts to provide a new direction and new data on the history of the Spanish language, in an grammar area as sensitive as the verbal system.

KEY WORDS: tense, historical grammar, pragmatics, verbal system, deixis.

\section{INTRODUCCIÓN}

Este artículo se enmarca en una investigación más amplia del modo indicativo realizada en la tesis doctoral: La temporalidad verbal en la segunda mitad del siglo XVI. Modo indicativo ${ }^{1}$. La investigación ha sido un trabajo de gramática a posteriori, cuyo objetivo principal ha sido la descripción sincrónica del sistema verbal del periodo mencionado en relación con la temporalidad verbal, desde el marco teórico de la Pragmática Histórica y de la Lingüística del Corpus².

En dicha tesis se estudia la temporalidad verbal del modo indicativo en un periodo que prácticamente coincide con el reinado de Felipe II y con los autores de la primera mitad de nuestro Siglo de Oro ${ }^{3}$, un periodo en el que, en palabras del profesor Lapesa, "la expectación del mundo civilizado estuvo pendiente de la irrupción española"4 y la lengua española alcanzó una extraordinaria difusión ${ }^{5}$, a la par que se completaba la unificación de la lengua literaria ${ }^{6}$.

Los usos directos e indirectos que aquí exponemos del presente de indicativo proceden del análisis en el nivel del enunciado de todos los presentes del corpus de la investigación. Hemos tenido en cuenta para estudiar la temporalidad del modo indicativo el modelo de análisis textual de la profesora Catalina Fuentes Rodríguez ${ }^{7}$, por lo que en la tesis se aborda también el análisis del comportamiento de los tiempos del modo indicativo en los niveles de la superestructura y de la macroestructura textuales, aunque esos resultados no se incluyen en este artículo ${ }^{8}$.

\footnotetext{
${ }^{1}$ Cuadrado Gómez, Carlos (2011): La temporalidad verbal en la segunda mitad del siglo XVI. Modo indicativo, UNED, Madrid, Biblioteca Central de la UNED, sign. TD04625.

${ }^{2}$ Desde el enfoque de la Pragmática Histórica, pretendemos hacer una descripción gramatical de la temporalidad del verbo en la 2. ${ }^{a}$ mitad del siglo XVI. Pero son muchos los estudios realizados sobre la morfología y la evolución del verbo español desde el latín hasta nuestros días, imprescindibles como punto de partida para cualquier tipo de descripción gramatical. Cf. Alvar, Manuel y PotTIER, Bernard (1987): Morfología histórica del español, Madrid, Gredos; GARCía-MACHO, M. ${ }^{a}$ Lourdes y PENnY, Ralph (2001): Gramática histórica de la Lengua Española. Morfología, Madrid, UNED; LAPESA, Rafael (2000): «Morfosintaxis histórica del verbo español», en Rafael Lapesa, Estudios de morfosintaxis histórica del español, vol. 2, edición de Rafael Cano Aguilar y M. ${ }^{\text {a Te- }}$ resa Echenique Elizondo, Madrid, Gredos. pp. 730-885.

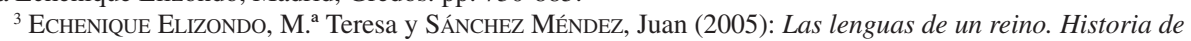
la Lingüística Hispánica, Madrid, Gredos, p. 321.

${ }^{4}$ LAPESA, Rafael (1980): Historia de la Lengua Española, Madrid, Gredos, p. 291.

${ }^{5}$ LAPESA, Rafael, op. cit. p. 293.

${ }^{6}$ LAPESA, Rafael, op. cit. p. 297.

${ }^{7}$ Cf. Fuentes RodrígueZ, Catalina (1996a): Aproximación a la estructura del texto, Málaga, Librería Ágora; (1996b): La sintaxis de los relacionantes supraoracionales, Madrid, Arco Libros; (1996c): Ejercicios de sintaxis supraoracional, Madrid, Arco Libros; (1999): La organización informativa del texto, Madrid, Arco Libros; (2000): Lingüística pragmática y análisis del discurso, Madrid, Arco Libros.

${ }^{8}$ En la tesis doctoral también se estudia el comportamiento de los tiempos del modo indicativo en relación con la perspectiva discursiva que divide el sistema verbal en tiempos del mundo comentado y tiempos del mundo narrado. Cf. WeInRICH, H. (1974): Estructura y función de los tiempos en el lenguaje, Madrid, Gredos, pp. 61-94.
} 


\section{CONCEPTOS TEÓRICOS ${ }^{9}$}

La temporalidad verbal es un concepto que se corresponde con el tiempo verbal situacional, en contraposición al tiempo verbal extensional o aspecto verbal ${ }^{10}$. Se define como una categoría gramatical deíctica, mediante la cual se expresa la orientación del contenido léxico del verbo con respecto al punto central u origen (normalmente el momento de la enunciación) o con respecto a una referencia secundaria que, a su vez, está orientada directa o indirectamente con respecto al punto origen (que es el centro deíctico) ${ }^{11}$.

Uno de los puntos de partida del concepto de temporalidad verbal es la obra de Reichenbach (1947 y 1948), que propuso un sistema sobre tres puntos: el punto del evento, el punto del habla y el punto de referencia. Lo explicaba mediante el siguiente ejemplo:

From a sentence like «Peter had gone» we see that the time order expressed in the tense does not concern one event, but two events, whose positions are determined with respect to the point of speech $(S)$. We shall call these time points the point of the event $(E)$ and the point of reference $(R)$. In the example, the point of the event is the time when Peter went; the point of reference is a time between this point and the point of $\operatorname{speech}^{12}$.

A partir de este sistema, se gestaron conceptos como el de centro deíctico y el de temporalidad absoluta y relativa, todos ellos en relación con el carácter deíctico de la temporalidad verbal.

Nosotros consideramos que el centro deíctico o punto origen siempre es el momento de la enunciación, coincidente con el momento de la emisión del hablante, sea esta oral o escrita. A partir de este instante, que es inequívoco y real, se desarrollan los otros puntos de referencia (alocéntricos). Los casos de recepción diferida no alteran en nada este momento enunciativo. En la Gramática Histórica trabajamos con textos escritos y, por lo tanto, siempre somos receptores diferidos. Gracias al principio de colaboración ${ }^{13}$, los hablantes adoptamos un sistema de suposiciones que nos permite jugar con un "momento enunciativo imaginario", en el que el hablante se dirige al oyente y en torno al cual gira el sistema verbal, por lo que siempre es posible la ubicación temporal

\footnotetext{
${ }^{9}$ Hacemos una somera exposición de los principales contenidos teóricos necesarios para comprender los resultados de la investigación, pero sin entrar en las controversias teóricas que se han originado a partir de cada concepto. Estas controversias pueden seguirse en los capítulos de la tesis dedicados al marco teórico y a las conclusiones.

${ }^{10}$ Porto Dapena, José Álvaro (1989): Tiempos y formas no personales del verbo, Madrid, Arco Libros, $\mathrm{p}$. 20.

${ }^{11}$ Diferentes autores tratan la cuestión de la temporalidad, entre otros: BuLL, W. E. (1960): Time. Tense and the Verb. A Study in Theoretical Linguistics, whit Particular Attention to Spanish, Berkeley, University of California Press; COMRIE, Bernard (1985): Tense, Cambridge, Cambridge University Press; PoRTO DAPENA, José Álvaro (1989): Tiempos y formas no personales del verbo, Madrid, Arco Libros.; ROJO, Guillermo (1990): «Relaciones entre temporalidad y aspecto en el verbo español», en I. Bosque (ed.), Tiempo y aspecto en español, Madrid, Cátedra pp. 17-45; RoJo, Guillermo y VEIGA, Alexandre (1999): «El tiempo verbal. Los tiempos simples», en I. Bosque y V. Demonte (dirs.), Gramática descriptiva de la lengua española, Vol. 2, Madrid, Espasa Calpe, pp. 2867-2934; Gutiérrez Araus, M. ${ }^{a}$ Luz (1997): Formas del pasado en indicativo, Madrid, Arco Libros; LóPEZ GARCíA, Ángel (1990): «La interpretación metalingüística de los tiempos, modos y aspectos del verbo español: ensayo de fundamentación», en I. Bosque (ed.), Tiempo y aspecto en español, Madrid, Cátedra, pp.107176; LyONs, John (1997): Semántica lingüística. Una introducción, Barcelona, Paidós, pp. 338ss.

${ }^{12}$ ReICHENBACH, Hans (1947): Elements of Symbolic Logic, London, Colliers-Macmillan, p. 288.

${ }^{13}$ Escandell Vidal, M. ${ }^{a}$ Victoria (1993): Introducción a la Pragmática, Madrid, UNED-Anthropos, p.92.
} 
del contenido léxico de la forma verbal. Un acuerdo tácito entre el escritor y el lector permite que se lean los textos como si en ese momento se estuviera produciendo una comunicación oral directa o como si estuviéramos siguiendo la escritura del autor, detrás de él, en el instante mismo en que está escribiendo. Igualmente en los textos escritos dialogados (secuencias dialogales) el autor nos coloca como observadores directos de los actos comunicativos de los personajes, como si se estuviesen produciendo en el mismo momento de la lectura, de modo similar a lo que ocurre con un espectador en el teatro o en el cine, cuando contempla la acción dramática en el escenario o en la pantalla como si fuera la primera vez que se produce.

Teniendo en cuenta a Bull ${ }^{14}$, podemos considerar estas relaciones temporales como vectores (V), conviniendo que $-\mathrm{V}$ simboliza la anterioridad, oV la simultaneidad y $+\mathrm{V}$ la posteridad. Si llamamos O (de origen) al punto central de todas las relaciones (el momento de la enunciación), nos encontramos con que las tres relaciones inicialmente posibles entre un acontecimiento y el punto cero (centro deíctico) son simbolizables también mediante las expresiones: $\mathrm{O}-\mathrm{V}$ (anterior al origen), OoV (simultáneo al origen) y $\mathrm{O}+\mathrm{V}$ (posterior al origen) ${ }^{15}$. Para resumir en una fórmula el valor temporal de una forma verbal, bastará con indicar la relación expresada y el punto con respecto al cual se refiere la relación, manteniendo la convención habitual de situar lo anterior a la izquierda y lo posterior a la derecha del origen ${ }^{16}$ :

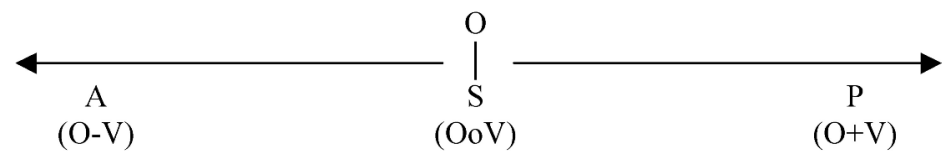

La existencia de relaciones temporales complejas procede del encadenamiento teóricamente ilimitado de escalones en cuanto a la relación que puedan establecer entre sí diferentes puntos de referencia. Podemos hablar de dos, tres y cuatro (¿por qué no más?) grados de encadenamiento. Con respecto a esos puntos de referencia las diferentes formas verbales establecen una relación de anterioridad, simultaneidad y posterioridad ${ }^{17}$ :

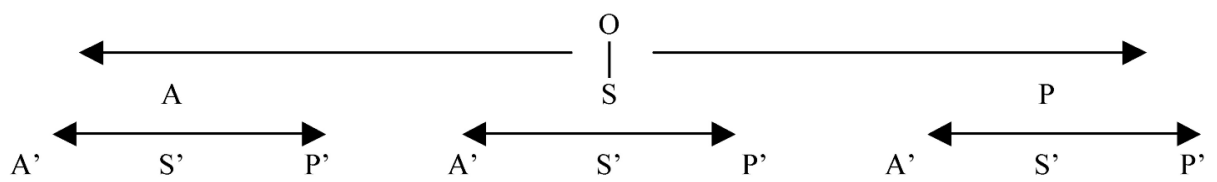

${ }^{14}$ Cf. Bull, W. E. (1960): Time. Tense and the Verb. A Study in Theoretical Linguistics, whit Particular Attention to Spanish, Berkeley, University of California Press.

${ }^{15}$ G. Rojo y A. Veiga, op. cit., p. 2876.

${ }^{16}$ Rojo, G. (1990): «Relaciones entre temporalidad y aspecto en el verbo español», en I. Bosque (ed.), Tiempo y aspecto en español, Madrid, Cátedra, p. 28.

${ }^{17}$ Veiga señala nueve funciones en el sistema verbal español, aplicando un sistema binarista en el que se establecen cuatro oposiciones temporales ( \pm anterioridad primaria, \pm anterioridad originaria, \pm vector único, \pm posterioridad). Cf. PÉREZ, M. ${ }^{a}$ Rosa (1998): El sistema verbal en Gonzalo de Berceo. Las formas de la irrealidad, Santiago de Compostela, Universidad de Santiago de Compostela, p. 32. 
En la lengua española llegamos al tercer grado de encadenamiento en el condicional compuesto $^{18}$.

La relación de anterioridad, simultaneidad y posterioridad respecto al punto origen (centro deíctico), o bien respecto a otro punto de referencia (alocéntrico) relacionado con este, es lo que determina la temporalidad absoluta y la temporalidad relativa ${ }^{19}$. Serían tiempos absolutos los que se relacionan directamente con el punto origen (vg. OoV para el presente, $\mathrm{O}-\mathrm{V}$ para el perfecto simple, $\mathrm{O}+\mathrm{V}$ para el futuro), y tiempos relativos serían los que se relacionan con un punto de referencia diferente del punto origen y relacionado con él (vg. (O-V)oV para el imperfecto, (O-V)-V para el pluscuamperfecto). Para referirnos a las relaciones mencionadas, hemos adoptado el modelo vectorial de Bull, que es el mismo que emplean Rojo y Veiga ${ }^{20}$.

Los valores o rasgos característicos de las formas verbales en cuanto miembros de un sistema o paradigma son diferentes de la casuística representada por las posibilidades combinatorias y los valores secundarios que esas formas adquieren en su uso particular en el discurso $^{21}$. Andrés Bello ya distinguía entre el significado fundamental y el significado metafórico de los tiempos y sostenía que, mediante los significados metafóricos, los significados fundamentales de unos tiempos son sustituidos o traspuestos a los significados de otros tiem$\operatorname{pos}^{22}$. Pérez Saldanya comparte la misma idea: los usos básicos responden al valor paradigmático de los tiempos (al valor que presentan dentro del sistema de oposiciones temporales y aspectuales), mientras que los usos derivados son traslaciones de estos valores básicos motivados por el contexto sintagmático en que aparecen los tiempos ${ }^{23}$. Son usos que no se explican por el propio sistema verbal, sino que es el discurso el que los posibilita ${ }^{24}$.

Consecuentemente, en el tiempo lingüístico y, por lo tanto, en el tiempo verbal hay que distinguir entre significado y referencia o designación ${ }^{25}$. El significado es el contenido que un signo posee en virtud de sus relaciones con los demás signos, por el hecho de pertenecer al sistema lingüístico. La referencia o designación depende del contexto o discurso, y se trata de la relación entre un signo y la realidad representada. Esto explica que un signo pueda tener un solo significado y un sinfín de referencias, y que dos o más signos de significado diferente puedan poseer idéntica referencia ${ }^{26}$. Hay que diferenciar, en consecuencia, entre el significado temporal, que constituye el tiempo verdaderamente

${ }^{18}$ Habría llegado $=((\mathrm{O}-\mathrm{V})+\mathrm{V})-\mathrm{V}$.

${ }^{19} \mathrm{~B}$. Comrie (1985: 36-82) diferencia varios casos posibles: absolute tense, relative tense, y, dentro de este último, pure relative tense y absolute-relative tense. Pero nosotros consideramos que con dos categorías (temporalidad absoluta y temporalidad relativa) queda suficientemente explicada la cuestión.

${ }^{20}$ Según estos autores, estas fórmulas «deben ser leídas de derecha a izquierda respetando las convenciones indicadas. Así O-V se refiere a un acontecimiento que es anterior $(-\mathrm{V})$ al origen $(\mathrm{O})$. Una fórmula un poco más complicada como $(\mathrm{O}-\mathrm{V})+\mathrm{V}$ se refiere a un acontecimiento que es posterior $(+\mathrm{V})$ a otro acontecimiento que, a su vez, es anterior (-V) al origen $(\mathrm{O}) »$. Cf. G. Rojo y A. Veiga, op. cit., pp. 2876

${ }^{21}$ PoRTo Dapena, J. A., op. cit., p. 30.

${ }^{22}$ Bello, Andrés (1847): Gramática de la lengua castellana, Madrid, EDAF, 1984, pp. 200-222.

${ }^{23}$ PÉrez SAldanya, Manuel (2004): «Los tiempos verbales: dificultades teóricas y terminológicas», en L. García Fernández, ed. (2004): El pretérito imperfecto, Madrid, Gredos, p. 198.

${ }^{24}$ GutiérRez Araus, M. ${ }^{a}$ Luz (1997): Formas del pasado en indicativo, Madrid, Arco Libros, 2. a edición, p. 38.

${ }^{25}$ Porto Dapena, J. A., op. cit., p. 14. Este autor cita a E. Coseriu (1977): Principios de semántica estructural, Madrid, Gredos, pp. 130-131, 163, 185ss.

${ }^{26}$ Posiblemente esta es la razón principal de la existencia de los usos primarios y secundarios de los tiempos verbales en un determinado sistema verbal. En los usos secundarios o contextuales dos tiempos pueden 
lingüístico o más específicamente verbal, y la referencia concreta de una forma del verbo a un tiempo de la realidad (tiempo físico-tiempo cronológico). Esto quiere decir que una forma de presente de indicativo, por ejemplo, no es presente por referirse al momento en que hablamos, lo cual constituye un fenómeno de referencia, sino más bien al contrario: se puede referir al momento en que hablamos porque significa presente.

En las formas verbales la indicación del tiempo no es parte de su significado nuclear, esencial o básico, expresado léxicamente, sino que es un significado meramente circunstancial, accidental, y su expresión se realiza mediante medios morfológicos. El verbo lo que hace es situar la acción o proceso -que constituye su significado nuclear, expresado por su base léxica- en relación con el tiempo externo ${ }^{27}$. En esto consiste el carácter deíctico de la temporalidad verbal.

La terminología para referirse a este fenómeno lingüístico es muy variada: significado fundamental y significado metafórico (Andrés Bello, 1847), significado y uso de los tiempos verbales (Esbozo, 1973), usos paradigmáticos y usos sintagmáticos (Porto Dapena, 1989), valores primarios y valores secundarios (Gutiérrez Araus, 2000), valores rectos y valores dislocados (Rojo y Veiga, 1999), usos básicos y usos derivados (Pérez Saldanya, 2004), etc. Nosotros preferimos los términos usos directos y usos indirectos. Al referirnos a algunos usos indirectos del presente, indicaremos que asume valores de otro tiempo verbal, dando a entender que toma para sí el vector temporal del uso directo de ese otro tiempo.

El modo indicativo del sistema español actual nos ha servido de punto de referencia para nuestra investigación, de manera que consideramos usos directos los que se exponen en el siguiente cuadro:

Modo INDICATIVO: TEMPORALIDAD ABSOLUTA Y RELATIVA (ESPAÑOL ACTUAL) ${ }^{28}$

\begin{tabular}{|c|c|c|c|}
\hline Temporalidad & Nivel de encadenamiento & Tiempo verbal & Esquema vectorial \\
\hline \multirow{3}{*}{ ABSOLUTA } & \multirow{3}{*}{1} & Presente & $\mathrm{OoV}$ \\
\cline { 3 - 4 } & & Perfecto simple & $\mathrm{O}-\mathrm{V}$ \\
\cline { 3 - 4 } & & Futuro simple & $\mathrm{O}+\mathrm{V}$ \\
\hline \multirow{5}{*}{ RELATIVA } & \multirow{4}{*}{2} & Imperfecto & $(\mathrm{O}-\mathrm{V}) \mathrm{oV}$ \\
\cline { 3 - 4 } & \multirow{3}{*}{} & Condicional simple & $(\mathrm{O}-\mathrm{V})+\mathrm{V}$ \\
\cline { 3 - 4 } & & Perfecto compuesto & $(\mathrm{OoV})-\mathrm{V}$ \\
\cline { 3 - 4 } & & Pluscuamperfecto & $(\mathrm{O}-\mathrm{V})-\mathrm{V}$ \\
\cline { 3 - 4 } & & Pretérito anterior & $(\mathrm{O}-\mathrm{V})-\mathrm{V}$ \\
\cline { 3 - 4 } & & Futuro compuesto & $(\mathrm{O}+\mathrm{V})-\mathrm{V}$ \\
\cline { 2 - 4 } & 3 & Condicional compuesto & $((\mathrm{O}-\mathrm{V})+\mathrm{V})-\mathrm{V}$ \\
\hline
\end{tabular}

CUADRO 1

\footnotetext{
coincidir en la misma referencia deíctica. Por ejemplo, el presente puede situar un evento en un momento posterior al centro deíctico como si fuera un futuro simple.

${ }^{27}$ Según Alarcos Llorach, «[incluso] sin que haya una temporalidad objetiva expresada en la frase (mediante adverbios o complementos) hay siempre en el pensamiento del que habla una temporalidad, y esta hará, según su valor, escoger la forma [verbal] que más convenga a su significado». Cf. AlarCos LlORACH, E. (1980): Gramática de la lengua española, Madrid, Espasa Calpe, p. 30.

${ }^{28}$ Cf. Rojo, G. y VeigA, A., op. cit., pp. 2869-2978; RAE (2009): «El verbo (I). Tiempo y aspecto léxico. Los tiempos del modo indicativo», en RAE, Nueva gramática de la lengua española, Madrid, Espasa Libros, pp. 1673-1795.
} 


\section{CoRpus y DATOS ESTAdísticos}

El corpus de la investigación ${ }^{29}$ está integrados por siete obras, cuyos criterios de selección, de modo sintético, han sido los siguientes:

1. Textos editados por primera vez entre 1551 y 1660 .

2. Textos escritos en prosa.

3. Variedad de tipos textuales (superestructura), atendiendo a la obra como macroacto de habla y a la variedad de secuencias.

4. Textos con amplia difusión entre los lectores de aquella época.

5. Textos de fácil acceso a sus primeras ediciones.

6. Estudio de obras completas o íntegras.

7. Obras impresas (con una sola excepción: Escritos desde de la cárcel, año 1572, de Fray Luis de León).

Por orden cronológico, las siete obras seleccionadas han sido ${ }^{30}$ :

OBRAS DEL CORPUS

\begin{tabular}{|c|c|c|c|c|}
\hline Título & Autor & Fecha & Tipo textual & $\begin{array}{c}\text { Secuencias } \\
\text { predominantes }\end{array}$ \\
\hline $\begin{array}{l}\text { Brevísima relación de la } \\
\text { destruición de las Indias }\end{array}$ & $\begin{array}{c}\text { Fray Bartolomé } \\
\text { de las Casas }\end{array}$ & 1552 & $\begin{array}{l}\text { Obra de denuncia } \\
\text { social, crónica } \\
\text { histórica }\end{array}$ & $\begin{array}{l}\text { Narrativas, } \\
\text { expositivas }\end{array}$ \\
\hline $\begin{array}{l}\text { La vida de Lazarillo de Tormes } \\
\text { y de sus fortunas y adversidades }\end{array}$ & Anónimo & 1554 & $\begin{array}{c}\text { Narrativa de } \\
\text { ficción, novela } \\
\text { picaresca }\end{array}$ & Narrativas \\
\hline El Deleytoso & Lope de Rueda & 1567 & $\begin{array}{l}\text { Teatro breve en } \\
\text { prosa, entremeses }\end{array}$ & Dialogales \\
\hline Registro de Representantes & Ioan Timoneda & 1570 & $\begin{array}{l}\text { Teatro breve en } \\
\text { prosa, entremeses }\end{array}$ & Dialogales \\
\hline Libro de la Oración & $\begin{array}{l}\text { Fray Luis de } \\
\text { Granada }\end{array}$ & 1572 & $\begin{array}{l}\text { Teológico- } \\
\text { religioso }\end{array}$ & $\begin{array}{c}\text { Narrativas, } \\
\text { expositivas, } \\
\text { instruccionales }\end{array}$ \\
\hline Escritos desde la cárcel & Fray Luis de León & 1572 & $\begin{array}{l}\text { Defensa jurídico- } \\
\text { teológica }\end{array}$ & $\begin{array}{l}\text { Narrativas, } \\
\text { expositivas }\end{array}$ \\
\hline $\begin{array}{c}\text { Thesoro de Pobres y Regimiento } \\
\text { de Sanidad }\end{array}$ & $\begin{array}{l}\text { Anónimo y } \\
\text { Arnaldo de } \\
\text { Villanova }\end{array}$ & 1594 & $\begin{array}{l}\text { Medicina, } \\
\text { divulgación } \\
\text { científica }\end{array}$ & $\begin{array}{l}\text { Instruccionales, } \\
\text { expositivas }\end{array}$ \\
\hline
\end{tabular}

CUADRO 2

${ }^{29}$ Sobre la teoría del corpus pueden consultarse las siguientes obras: BARCO ADALID, M. ${ }^{\text {a }}$ Teresa (2000): $L a$ Lingüística del Corpus: Creación de un corpus de textos turísticos, memoria de investigación dirigida por el Dr. D. F. Miguel Martínez Martín, Biblioteca Central de la UNED, sig. 2731; AARTs, J. y MeIJs, W. (1984): Corpus linguistic, Amsterdam, Rodopi; Alvar EzQuerra, M. y CorPas PAStor, G. (1994): Estudios para un corpus del español, Málaga, Universidad de Málaga.

${ }^{30}$ Las siglas empleadas son: BR: Brevísima relación; LA: Lazarillo; DE: El Deleytoso; RR: Registro de Representantes; LO: Libro de la Oración; FLC: Fray Luis desde la cárcel; TH: Thesoro de Pobres y Regimiento de Sanidad. 
El corpus cuenta con un total de 28.891 formas verbales. De estas, el 82,6\% son formas personales y el 17,4\%, formas impersonales. En el grupo de las formas personales, el indicativo supone el 70,50\%, seguido del subjuntivo, con un 15,9\%, y del imperativo, con un 13,6 \% $\%^{31}$. Dentro de los tiempos del modo indicativo, el presente representa el $48,27 \%$, con un total de 8.107 formas verbales. El presente es el tiempo más utilizado, seguido del perfecto simple $(21,58 \%)$. Para hacernos una idea global de la alta frecuencia del presente de indicativo, en el siguiente cuadro presentamos el número total del formas verbales de cada obra, la frecuencia de presentes y el porcentaje que suponen dentro del grupo de los tiempos del modo indicativo:

DATOS ESTADÍSTICOS DEL CORPUS

\begin{tabular}{|l|c|c|c|}
\hline \multicolumn{1}{|c|}{ OBRAS } & $\begin{array}{c}\text { N. }{ }^{\circ} \text { TOTAL } \\
\text { ENTRADAS }\end{array}$ & $\begin{array}{c}\text { N. }{ }^{\text {o }} \\
\text { PRESENTES }\end{array}$ & $\begin{array}{c}\% \\
\text { PRESENTES }\end{array}$ \\
\hline Brevísima relación & 4.702 & 937 & $30,29 \%$ \\
\hline Lazarillo de Tormes & 3.502 & 598 & $25,54 \%$ \\
\hline El Deleytoso & 1.719 & 678 & $63,50 \%$ \\
\hline Registro de Representantes & 1.886 & 774 & $67,66 \%$ \\
\hline Libro de la Oración & 6.862 & 2.417 & $55,65 \%$ \\
\hline Escritos desde la cárcel, 1572 (Fray Luis de León) & 2.964 & 841 & $40,71 \%$ \\
\hline Thesoro de Pobres y Regimiento de Sanidad & 7.256 & 1.862 & $67,37 \%$ \\
\hline TOTAL ENTRADAS & 28.891 & 8.107 & $48,27 \%$ \\
\hline
\end{tabular}

TABLA 1

A la hora de investigar los usos directos e indirectos del presente de indicativo, hemos examinado una a una cada forma verbal de este tiempo. Inferimos el uso de una determinada forma verbal analizando el enunciado donde está inserta (microestructura); en dicho enunciado aparecen otras formas verbales y otros complementos que inciden en ella ${ }^{32}$. Simultáneamente, cada forma verbal se inserta en una secuencia (superestructura) y en un párrafo (macroestructura). Estamos ante un trabajo de gramática a posteriori mediante un corpus escrito $^{33} \mathrm{y}$, por lo tanto, incluimos en el artículo ejemplos significativos de todos los usos que atestiguamos.

${ }^{31}$ El elevado porcentaje de imperativos se debe a su altísima frecuencia en la obra médica (Thesoro de Pobres y Regimiento de Sanidad), donde predominan las secuencias instruccionales.

${ }^{32}$ La Pragmática estudia los principios que regulan el uso del lenguaje, incluidas las condiciones que determinan el empleo de enunciados concretos. El enunciado es el mensaje construido según el código lingüístico: está enmarcado entre dos pausas y delimitado por el posible cambio de emisor.

${ }^{33}$ Hemos manejado las ediciones que se indican en el CUADRO 2. El criterio general de transcripción de citas textuales es respetar la ortografía de las obras originales, con todas sus variantes, a excepción de la acentuación, que actualizamos, o la transcripción de la «s larga» como «s corta o corriente». Resolvemos todas las abreviaturas. El presente que nos interesa en cada ejemplo se transcribe en cursiva y otros elementos que queremos resaltar (verbos, complementos, etc.) se subrayan. 


\section{USOS DIRECTOS DEL PRESENTE DE INDICATIVO}

En sus usos directos, como tiempo absoluto, el presente señala una acción simultánea al momento de la enunciación. Su esquema vectorial es: OoV. La fugacidad del instante de la enunciación complica a veces el hecho de encontrar usos primarios evidentes, pues el periodo de tiempo que el hablante psicológicamente considera "presente" admite una amplitud variable, por lo que frecuentemente nos movemos en una zona de ambigüedad entre los usos primarios y los secundarios. La simultaneidad indudable de la acción verbal respecto del centro deíctico se da cuando es posible la sustitución de la forma verbal en presente por la perífrasis estar + gerundio. Esta sustitución nos revela los dos usos directos del presente: el presente actual y el presente durativo.

El presente actual es el uso directo más claro. Se manifiesta en contextos en los que la palabra es acción o la palabra se superpone prácticamente a la acción. En el primer caso, el presente se inserta en peticiones o súplicas, aserciones, confesiones, juramentos y órdenes:

«Suplico a vuestra Merced resciba el pobre seruicio de mano de quien lo hiziera más rico:», LA, a3r, 51 (súplica).

«Y más affirmo que hasta que todas estas muchedumbres de gentes de aquella ysla fueron muertas $\tau$ assoladas $[\ldots]$ no cometieron contra los christianos vn solo pecado mortal [...]», BR, b1v, 151 (aserción).

«Quando se hizo el ensayo confiesso mi pecado, que también fuy dello espantado [...]», LA, h3r, 286 (confesión).

«Alam. Yo juro a los huessos de mi bisagüela la tuerta, que ni miré ni tenían suelos ni suelas, ni an tejados, mas no digo yo que fuera de puro afrecho como tú dices [...]», DE, a3r, 6366 (juramento).

«Y por la presente vos damos licencia y facultad para que [...] podáys imprimir y vender los dichos libros que de suso se haze mención: y mandamos que [...] qualquier impresor destos nuestros reynos y señoríos que vos quisiéredes y señaláredes, imprima los dichos libros y que otra persona ninguna no los pueda imprimir ni vender sin vuestra licencia [...]», LO, 6, 1924 (orden o mandato).

En el segundo caso, cuando la palabra y la acción se superponen o suceden casi simultáneamente, el presente actual se utiliza para expresar: la acción en curso, anotaciones teatrales, secuencias dialogales, opiniones, recuerdos instantáneos y puntuales, intenciones o deseos inmediatos y fechas y periodos temporales.

Veamos ejemplos de todos estos supuestos:

«Sama. [...] ta, ta, quiero dissimular, que he lo aquí do viene», DE, d1v, 75-77 (expresión de la acción en curso).

«Entra Cilena pastora.», RR, e3r, 81 (anotación teatral).

«Mas o Saluador mío qué hazéys, que no days parte de vuestra gloria a aquel cuerpo sanctíssimo, que os está aguardando en el sepulchro?», LO, 410, 439 (secuencia dialogal).

«Más oro robaron en aquel tiempo de aquel reyno (alo que yo puedo juzgar) de vn millón de castellanos: y creo que me acorto:», BR, b5v, 90-91 (opinión). 
«[...] esto descontentó al maestro León. pero acuérdome que el maestro francisco sancho lo aprouó.», FLC, fol. 138r, 376 (recuerdo instantáneo y puntual).

«Mas tambien quiero que sepa Vuestra Merced, que con todo lo que adquiría [...]», LA, a7v, 203 (deseo inmediato).

«[...] son en Salamanca 13 de março de 1572.», FLC, fol. 112v, 41 (fecha).

«[...] por manera que $h a$ quarenta $\tau$ nueue años que fueron cantidad de españoles $[. .]$.$» ,$ BR, a4r, 5 (periodo temporal).

El presente actual ejerce de conector textual solo cuando señala una acción simultánea al centro deíctico, pues, como veremos en los usos secundarios, el presente puede adoptar el esquema vectorial de un perfecto compuesto en la función de conexión textual. Como conector textual, el presente actual se superpone a las palabras que se están pronunciando, escribiendo o leyendo. Podríamos hablar de una "autoconexión, como si dos planos o niveles se solaparan o se fusionasen en el momento de la enunciación. Con el presente se expresa el acto comunicativo en curso, se anticipan los planes del discurso, se explica lo que se acaba de decir o se refuerza lo que se está diciendo. Si hay una referencia a un momento anterior del discurso, este es tan inmediatamente anterior que se confunde con el momento enunciativo. El verbo más empleado es decir:

«Y poresto $\tau$ por otras cosillas que no digo salí dél.», LA, g4r, 19 (acto comunicativo en curso).

«Y como digo él estaua entre ellas hecho vn macías [...]», LA, e6r, 321 (refuerzo del propio discurso).

«Y a la hora de nona clamó Iesús con gran voz diziendo: Elí, Elí, lamazabachthaní: que quiere dezir: Dios mío Dios mío, porqué me desamparaste?», LO, 299, 127 (explicación del texto).

«Dos o tres quiero dezir solamente / por las quales se juzguen otras ynnumerables en número y fealdad que fueron dignas de todo tormento y fuego.», BR, d7v, 15 (planes de desarrollo discursivo).

El presente durativo es un uso directo porque es posible la sustitución de la forma verbal en presente por la perífrasis estar + gerundio, como decíamos más arriba ${ }^{34}$. Puede haber confusiones entre el presente durativo y el presente habitual, el presente descriptivo y el presente de existencia. En los cuatro supuestos el tiempo de la enunciación abarca un periodo de tiempo más amplio que el instante mismo del habla. Sin embargo, pensamos que para el presente durativo se reservan acciones que rebasan el límite del centro deíctico, pero tienen una duración limitada, y para las que el hablante tiene una percepción de presente transitorio, aunque no exactamente momentáneo. En el presente durativo los verbos de conocimiento (saber, conocer) expresan un estado psíquico presente, pero no es un movimiento mental iniciado o producido en el momento de la enunciación, contrariamente a lo que sucede con el presente actual. En algunas construcciones con el verbo tener, solo o integrado en las perífrasis tener + participio, tener $a+$ infinitivo, tener + adjetivo, el presente es claramente durativo ${ }^{35}$. Pasemos a los ejemplos:

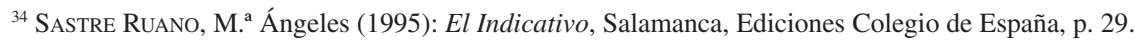

${ }^{35}$ Hacemos esta aclaración porque, como veremos más adelante, este tipo de construcciones también puede tener el valor de un perfecto compuesto.
} 
«Esto sé por relación y palabras del mismo almirante.», BR, a8v, 72.

« $\tau$ oy no cessan de hazerlas [sic] / y quasi tienen despobladas todas aquellas trezientas leguas / que estauan (como se dixo) tan llenas y pobladas.», BR, d2v, 48.

«Y la otra: consideraua $\tau$ dezía. Yo he tenido dos amos: el primero traýa me muerto de hambre, $\tau$ dexando le topé con estotro que me tiene ya con ella en la sepoltura:», LA, c5r, 158.

«[...] dixo me el ciego. Lázaro esta agua es muy porfiada $\tau$ quanto la noche más cierra más recia:», LA, b8v, 586-587.

«[...] $\tau$ assí me casé con ella $\tau$ hasta agora no estoy arrepentido, porque aliende de ser buena hija, $\tau$ diligente seruicial: tengo en mi señor el Arcipreste todo fauor $\tau$ ayuda:», LA, h5v, 51-53.

«Luc. Pues hermano Alameda por tu vida que mires por la honrra dentramos [sic], pues te va tanto a ti, como a mí.», DE, a4r, 124.

«Mart. [...] sane mi muger, que yo le prometo vn ganso que tengo a engordar.», DE, b5r, 31.

«Cola. [...] tengo entendido que ha de venir hoy vna muger de Ruçafa que tiene su madre mala.», RR, a2v, 25.

«Y después acá para el mismo fin se an ofrecido otras dos cosas que me conuiene probar [...]», FLC, fol. 218r, 8 .

«[...] es papel que importa para entendimiento de algunas cosas delas que ayer declaré.», FLC, fol. 144r, 121.

«Por esto con mucha razón se marauillan los Ángeles desta tan estraña fealdad: [Cristo en la cruz]», LO, 134, 322.

«Mas agora conozco en esto mi flaqueza: porque no es vencer la ira huyr de la compañía, sino cubrir la imperfectión.», LO, 335, 821.

«Es el precio tan poco que es dado, / pues en compendio tienes tal thesoro, / que en sí tiene materia peregrina, / y para todo mal medicina.», TH, 2r, 6 (octava).

\section{USOS INDIRECTOS DEL PRESENTE DE INDICATIVO}

El presente es el tiempo más versátil del modo indicativo. Seguramente a causa de su estrecha vinculación con el momento enunciativo, el presente puede desplazar sus valores temporales a lo largo de toda la línea temporal (anterioridad vs. posterioridad), sin llegar a perder completamente su carácter de simultaneidad respecto al centro deíctico ${ }^{36}$.

Hemos dividido los usos indirectos del presente en cuatro grupos:

\footnotetext{
${ }^{36}$ Recordamos que, cuando utilizamos expresiones como «presente con valor de perfecto compuesto", queremos decir que el presente asume la temporalidad directa de ese tiempo (o.V.)-V.
} 
USOS INDIRECTOS DEL PRESENTE DE INDICATIVO

\begin{tabular}{|c|l|}
\hline Vector & \multicolumn{1}{|c|}{ Usos } \\
\hline ANTERIORIDAD & $\begin{array}{l}\text { - Presente histórico } \\
\text { - Presente con valor de perfecto compuesto } \\
\text { - Presente como conector textual con valor de pasado } \\
\text { - Presente con valor de pretérito imperfecto } \\
\text { - Presente con valor de condicional simple }\end{array}$ \\
\hline POLOR DE PASADO) & $\begin{array}{l}\text { - Presente con valor de futuro en construcciones de futuro analítico } \\
\text { - Presente con valor de futuro en construcciones perifrásticas } \\
\text { (VALOR DE FUTURO) }\end{array}$ \\
\hline IMPERATIVO & - Presente con valor de futuro sin perífrasis verbales \\
\hline OTROS imperativo \\
\hline DISCURSIVOS & $\begin{array}{l}\text { - Presente habitual } \\
\text { - Presente descriptivo } \\
\text { - Presente de existencia } \\
\text { - Presente hipotético y enfatizador } \\
\text { - Presente permanente } \\
\text { - Presente para citas de textos escritos }\end{array}$ \\
\hline
\end{tabular}

CUADRO 3

Dentro de la temporalidad de anterioridad, destaca el uso del presente histórico, que aparece en secuencias narrativas, asumiendo la temporalidad propia del perfecto simple: $\mathrm{O}-\mathrm{V}$. Es frecuente en nuestro corpus que en una misma secuencia narrativa se alterne el presente histórico con el perfecto simple, e incluso con otros tiempos del pasado. No hemos encontrado ningún presente histórico en las dos obras teatrales, El Deleytoso y Registro de Representantes; es posible que el motivo de esta ausencia radique en que el presente histórico requiere una secuencia narrativa más elaborada en la mente del hablante y la rapidez del intercambio comunicativo de las secuencias dialogales de estas obras, que son muy coloquiales, no favorezca su uso. En el resto de las obras del corpus se atestiguan casos del presente histórico:

«[...] súbitamente se les reuistió el diablo alos christianos: $\tau$ meten a cuchillo en mi presencia (sin motiuo ni causa que tuuiessen) más de tres mil ánimas que estauan sentados delante de nosotros hombres $\tau$ mugeres y niños.», BR, b3v, 55 .

«Apenas auía acabado su oración el deuoto señor mío: quando el negro Alguazil cae de su estado $\tau d a \tan$ gran golpe enel suelo quela yglesia toda hizo resonar:», LA, g8v, 170.

«Y a todos parecieron bien. soloel [sic] maestro León parece que se repuntó.», FLC, fol. $139 \mathrm{v}, 415$.

«Desta manera llorauan y lamentauan toda aquella santa compañía, regando y lauando con lágrimas el cuerpo sagrado. Llegada pues ya la hora de la sepultura, embueluen el santo cuerpo en vna sáuana limpia: atan su rostro con vn sudario: y puesto encima de vn lecho, caminan con él al lugar del monumento, y allí depositan aquel precioso thesoro. El sepulcro se cubrió con vna losa, y el coraçón de la madre con vna escura niebla de tristeza.», LO, fol. 68r, 453-463.

El presente puede tener el valor de un perfecto compuesto, haciendo suyo su esquema vectorial: (OoV)-V. En este uso se suelen emplear perífrasis con participio, aunque hay casos sin perífrasis. El presente también puede funcionar como un perfecto com- 
puesto cuando ejerce de conector textual; a veces acompañan al presente complementos espaciales con valor temporal (arriba, de suso), debido precisamente al carácter espacial de los textos escritos:

«[...] esto en aquella letura que como he dicho tengo presentada y confesada antes que me prendiesen lo digo.», FLC, fol. 158r, 36 (con perífrasis).

«Cami. Señor beso las manos de vuessa mercé en la posada lo dexo aparejado.», DE, c3r, 110 (con perífrasis).

«Caço. [...] dezía: [...] y vista la información que resulta contra él, le mandamos dar dozientos açotes y desterrarlo:», RR, b2v, 126 (sin perífrasis).

«quiero dezir tres / o quatro no más: por los quales se podrán juzgar los que para effectuar las grandes destruyciones y despoblaciones que arriba dezimos: pueden auer hecho.», BR, e4r, 43 (conector textual).

También el presente puede situar una acción como simultánea a otra del pasado, asumiendo el valor de un imperfecto: $(\mathrm{O}-\mathrm{V}) \mathrm{oV}$. El verbo absoluto de referencia suele ser el perfecto simple, pero pueden ser otros. Las acciones reflejadas también pueden ser habituales y tener un carácter descriptivo:

«Cola. No te fatigues, pídele qué es lo que hazía quando su madre enfermó.», RR, a5v, 173.

«[...] mayormente viendo que los sanctos hazían esto más vezes, pues el Propheta Daniel tres vezes al día se recogía a este officio, y el Propheta Dauid siete vezes al día tiene por estilo alabar a Dios.», LO, 112, 1579.

El presente asume una temporalidad de posterioridad o tiene valor de futuro simple en varias circunstancias. Así ocurre en la estructura perifrástica del futuro analítico. En la segunda mitad del siglo XVI, conviven el futuro analítico y el futuro sintético. En el caso del futuro analítico la forma personal del verbo haber no ha perdido del todo su valor de presente. Algunos de los futuros analíticos forman parte de construcciones condicionales. Otros simplemente son acciones del futuro o son la consecuencia de una cadena de instrucciones, como en los ejemplos del Thesoro de Pobres y Regimiento de Sanidad. En algunos casos la temporalidad de posterioridad se ve reforzada en el enunciado por otros futuros sintéticos o complementos temporales:

«Responde el español vente comigo [sic] sino cortarte he las orejas:», BR, d2v, 65.

«[...] yo haría vna muy larga hystoria / pero esto quedarse ha para su tiempo si dios diere la vida.», BR, d6r, 47.

«[...] partillo hemos [el racimo de uvas] desta manera: tú picarás vna vez, $\tau$ yo otra:», LA, b4v, 408 .

«Respondió le Iesús, y díxole: Lo que yo hago, no lo sabes tú agora: saberlo has después», LO, 120, 57.

«[...] y muélelo y échalo en el diente que te doliere, y quitarte ha el dolor.», TH, 19r, 30.

«Dize Diascórides que tomes la bretónica y májala y ponla doquier que tuuieres los huessos quebrados y soldarlos ha.», TH, 55r, 17.

Con otras perífrasis de infinitivo, el presente también adquiere el valor de futuro (haber de, tener de, ir a, poder, querer + infinitivo). Cuando el presente forma parte de perífrasis 
con el infinitivo pospuesto, fácilmente adquiere una temporalidad de posterioridad respecto del momento enunciativo. El valor de futuro que se consigue con las perífrasis puede presentar distintas modalidades: de obligación, de posibilidad, de imposibilidad, de voluntad, etc. En algunos casos el presente está incorporado en construcciones condicionales:

«En las quales [conquistas] (ii se permitiessen) han de tornarse a hazer [las injusticias]:», BR 4, 39.

«Bárb. No lo entendéys? nouenas sentiende que tengo destar yo allá encerrada nueue días.», DE, b8r, 198.

«Iuan. Agora acote de do hauemos de saltar.», RR, b6v, 325.

«Y assí dixo entonces aquellas palabras. Cada vez que esto hiziéredes hazeldo en memoria de mí, para que os acordéys de lo mucho que os quise, y de lo mucho que voy a hazer y padescer por vuestra salud.», LO, 146, 571-572

«[...] torno a supplicar que se me dé vn cuchillo para cortar lo que como que por la misericordia de dios seguramente se me puede dar.», FLC, fol. 127r, 16.

Sin necesidad de perífrasis, el presente tiene valor de futuro en estructuras condicionales, situado tanto en la prótasis como en la apódosis, y en otro tipo de construcciones (causales, temporales...) con la ayuda de complementos temporales:

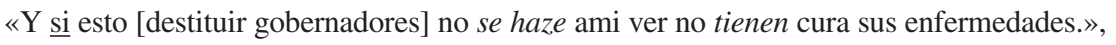
BR, d6r, 62 .

«Alam. Pues qué me harán, si me cogen?», DE, a8v, 99.

«Iuan. No quiero, esté se quedo, y dexe la cesta de los hueuos. Caço. Que luego bueluo.», RR, b6v, 342.

«Vuestra reuerencia me escriua quando llegue este mensajero. y ny más ny menos quando sale de allá.», FLC, fol. 112v, 45.

El presente puede tener valor de imperativo mediante el uso de perífrasis de infinitivo, del futuro analítico y del verbo ir (vamos). Cuando el presente se emplea con la modalidad de imperativo, mantiene su valor de simultaneidad, pero también contrae una temporalidad de posterioridad. La cualidad específica del modo imperativo es que en una sola forma verbal confluyen dos momentos temporales: el momento del mandato o de la súplica (vector de simultaneidad) y el momento de la realización (vector de posterioridad, generalmente):

«Salz. Vos proprio hauéys de venir, y si diéredes el descaro que conuenga, dexaros han que boluáys.», DE, b3v, 252. 29.

«[...] y cuézela con agua y darse la has a beuer ante que le venga la calentura:», TH, 57r,

«Mándales poner el toque y desque vido que eran cobre dixo alos españoles dad al diablo tal tierra vámonos pues que no ay oro:», BR, c6v, 98.

El presente tiene otros usos indirectos que se caracterizan por el estatismo propio de la descripción. Tienen un valor temporal permanente, puesto que pueden abarcar todo el arco temporal. Sobre el estatismo de la descripción dice Lausberg:

La «evidentia» $[\ldots]$ es la descripción viva y detallada de un objeto [...] mediante la enumeración de sus particularidades sensibles (reales o inventadas por la fantasía) [...]. El con- 
junto del objeto tiene en la «evidentia» carácter esencialmente estático, aunque sea un proceso [...]. Se trata de la descripción de un cuadro que, aunque movido en sus detalles, se haya contenido en el marco de una simultaneidad (más o menos relajable [sic] $)^{37}$.

Por ejemplo, en el caso del presente habitual, cuando esa "evidentia" se refiere a acciones frecuentes o habituales de un individuo o de un colectivo, el presente amplía su campo temporal a límites que superan sobradamente el momento enunciativo, y podemos decir que estamos ante la "descripción" de acciones y no ante una simple "narración" de acciones. Entonces el presente habitual se sitúa en secuencias descriptivas.

Entre estos usos indirectos están:

a) El presente habitual

En el presente habitual el contenido léxico de la forma verbal se sitúa en un periodo temporal más amplio que el comprendido en el centro deíctico. Es diferente al presente durativo, porque no se trata de una acción cuya duración rebasa tímidamente los límites del instante enunciativo. En el presente habitual las acciones son descritas, como si fueran el "fondo" del momento vital en el que se sitúa el centro deíctico. El hablante no pretende que coincida la acción verbal con el momento del habla, simplemente dicho instante está incluido en el periodo de la acción habitual, que viene de un pasado (remoto o cercano) y que continuará en el futuro (inmediato o diferido):

«Meten los enla mar en tres y en quatro $\tau$ en cinco braças de hondo desde la mañana hasta que se pone el sol: están siempre debaxo del agua nadando sin resuello arrancando las ostras donde se crían las perlas. Salen con vnas redezillas llenas dellas alo alto y arressollar [sic]: donde está vn verdugo español en vna canoa / o barquillo: $\tau$ si se tardan en descansar les $d a$ puñadas y por los cabellos los echa al agua para que tornen a pescar.», BR, e2v, 225-233.

«En el qual día de oy viuo y resido a seruicio de dios y de vuestra Merced. Y es que tengo cargo de pregonar los vinos que enesta ciudad se venden, y en almonedas $\tau$ cosas perdidas, acompañar los que padecen persecuciones por justicia, y declarar a bozes sus delictos, pregonero hablando en buen Romance.», LA, h5r, 25-33.

b) El presente descriptivo (lugares, personas, cosas, nombres)

Como queda dicho para el presente habitual, con el presente descriptivo la "realidad" se presenta como un cuadro estático, cuyos elementos son simultáneos para el observador y cuya temporalidad tiene un carácter de perdurabilidad que rebasa los márgenes del momento enunciativo. Se puede utilizar el presente descriptivo para describir lugares, personas, animales, objetos, etc. También se emplea para referirse a los nombres propios, a los nombres genéricos y a la terminología científica (plantas, enfermedades, etc.):

«Pana. Mira en la tierra de Xauxa hay vnos árboles que los troncos son de tozino. [...] Y las hojas son hojuelas, yel fruto destos árboles son buñuelos, y caen en aquel río dela miel, quellos mismos están diziendo máxcame, máxcame. [...] las calles están empedradas con yemas de hueuos [...]», DE, c7r, 121-130.

«[...] los bayles y danças que acostumbran y que llaman ellos Mitotes como enlas yslasllaman Areytos:», BR, c2v, 85-86.

${ }^{37}$ LAUSBerg, Heinrich (1966): Manual de retórica literaria, Vol. 2, Madrid, Gredos, p. 224. 
«Y acaeció que vn fraile que tenía cargo de mi celda que se llama frai Diego de León que agora está en la prouincia de Aragón [...]», FLC, fol. 97v, 51.

«[...] que tomes la raýz de los cogombros montesinos, que por otro nombre se llama cogombrillo amargo, y quémala [...]», TH, 3v, 39.

c) El presente de existencia

El presente de existencia comparte las mismas características que el presente descriptivo. Podemos decir que es una manera de describir sin enumerar las características de lo descrito, en la que se comunica al lector (u oyente en la lengua hablada) que "existe" determinado ser vivo, lugar, objeto o idea. Esa existencia no es efímera, lo "existente" existía antes del momento de la enunciación, existe en ese momento y continuará existiendo después. Es una realidad estática mientras no deje de "existir".

Los verbos empleados son el verbo ser y el verbo haber mediante su forma impersonal hay. También se utilizan otros verbos relacionados con la existencia, como vivir:

«De allí vanse ala prouincia de Tumbala ques enla tierra Firme $\tau$ matan y destruyen quantos pudieron.», BR, f1r, 33.

«Yne. [...] pues otras ay que no son para descalçarme el çapato y biuen más descansadamente que yo:», RR, b7v, 21.

«[...] que yo juraré sobre la hostia consagrada que es tan buena muger como viue dentro delas puertas de Toledo:», LA, h7r, 120.

«[...] y así le quemé aquella noche en my celda en vna chimenea que ay en ella.», FLC, fol. $142 \mathrm{v}, 578$.

d) El presente hipotético o enfático

En este uso el presente adquiere, en parte, una modalidad propia del modo subjuntivo. En cuanto a la temporalidad, estamos en el límite entre el uso primario y el uso secundario. El matiz de posibilidad hace que el momento en el que se ubica el contenido léxico del verbo pueda oscilar de la anterioridad a la posterioridad. Igualmente ocurre con el matiz enfático, que a veces es difícil diferenciar, o incluso separar, del valor hipotético. El presente empleado para expresar una acción verbal posible o enfática participa de las características del presente habitual, descriptivo y de existencia.

El contenido semántico de los verbos es muy importante en este uso secundario. Se emplean las perífrasis PODER + INFINITIVo (ser, haber, esperar, traer...), DEBER (DE) + INFINITIVO (ser, haber), HABER DE HABER. Se emplean algunos verbos, como dudar, que incorporan en su lexema el matiz hipotético:

«[...] aunque te digo, que después que en esta casa entré: nunca bien me ha ydo: deue ser [sic] de mal suelo, que ay casas desdichadas $\tau$ de mal pie, que los que viuen enellas pegan la desdicha: esta deue de ser [sic] sin duda dellas:», LA, e8r, 402-406.

«Alg. Vosotros ladrones deuéys de ser.», RR, c7v, 117.

«Y paréceme que en vn cartapacio mío a de auer otro lugar dela escrittura declarado [...]», FLC, fol. 160v, 41.

«Y finalmente coneste testamento y eneste cuydado ocupado murió el desdichado: y quién $d u d a$ que no esté enlos infiernos sepultado.», BR, d4r, 167. 
e) El presente permanente (gnómico, empírico, definiciones, verdades morales y teológicas, etc.)

Este presente permanente comparte las principales características de la temporalidad del presente descriptivo. Estaríamos ante un tipo de "estatismo" llevado al límite. El presente permanente se emplea para la expresión de verdades de índole personal y colectiva y que propiamente no tienen una ubicación concreta en la línea temporal, pues pueden "aplicarse" o situarse en cualquier momento de esa línea, incluido el centro deíctico. El presente permanente adquiere la temporalidad de la situación a la que es asociado por el hablante en su discurso:

«[...] arrimáuase a este refrán: más $d a$ el duro que el desnudo [...]», LA, b4r, 386.

« dixe le: señor el buen aparejo haze buen artífice [...]», LA, f1r, 442.

«Rodr. No ha oýdo dezir vuestra merced, quien quita la cláusula quita el pecado?», RR, c4v, 274.

«En el exercicio de la oración se alimpia el ánima de los peccados, apascienta se la charidad, alumbra se la fe, fortalesce se la esperança, alégrase el espíritu, derriten se las entrañas, pacifica se el coraçón [...]», LO, 76, 867-77, 873.

«Iten leyendo la materia de Eucharistía. tratté si el sacramento enlos que le reciben dignamente demás dela gracia que infunde enel alma. produze enel cuerpo alguna buena qualidad y inclinación alo bueno.», FLC, fol. 135v, 205.

«Sali. Ora venid acá, pues tanta habilidad es la vuestra, quántos son siete, ocho y nueue?», RR, b5v, 279.

«Las enfermedades de los hombres son departidas, bien assí como las complesiones de los hombres son partidas, según los quatro elementos de que somos criados, assí como el fuego, la tierra, el ayre, y el agua. Y cada vno participa según qué más o menos: y assí recuden las enfermedades.», TH, 56v, 1-6.

«ORACIÓN, propriamente hablando, es vna petición, que hazemos a Dios de las cosas que convienen a nuestra salud.», LO, 23, 2-4.

f) Presente para citas de textos escritos

Con los verba dicendi los autores de nuestro corpus frecuentemente citan a otros autores mediante estructuras de estilo directo (cita textual) o estilo indirecto. El texto escrito es un objeto material para el lector, al que accede, mediante la lectura, como quien contempla un cuadro o una escultura. Para el lector la comunicación se produce en el momento de de la lectura (recepción), y por eso emplea el presente cuando cita textos escritos, porque para él siempre "se está diciendo" lo que él mismo u otro lector pueden leer una o infinitas veces.

Este es un uso próximo al presente histórico, al presente permanente y al presente descriptivo o de existencia: al presente histórico porque el acto de escribir (decir) es anterior al momento de la lectura; al permanente porque lo que se dijo se dice y se seguirá diciendo, pues el "objeto" libro (carta, manifiesto, cartel, texto legal, etc.) no desaparece y las palabras citadas pueden ser leídas siempre; al descriptivo o de existencia porque el estatismo propio de esos usos indirectos se da en el acto mismo de citar, ya que el texto es inamovible y su existencia será imperecedera mientras no sea destruido el objeto libro.

Los verba dicendi empleados son decir, expresar, clamar, protestar, llamar, contener y hablar. 
En la obra médica Thesoro de Pobres y Regimiento de Sanidad hemos contabilizado 850 casos del presente para citas escritas. El autor emplea repetidamente la misma estructura: la forma verbal dize (u otras formas verbales similares) da paso a la cita de un sabio de la Antigüedad en la que, en secuencias instruccionales, se explican determinados remedios o procedimientos médicos. No obstante, encontramos este uso indirecto en más obras del corpus:

«[...] como lo hazían aquellos tiranos ladrones de quien dize el propheta zacharías. capítulo. II. Pace pecora ocisionis [...]», BR, d1v, 137.

«Y a este propósito dize Tulio La honra [sic] cría artes.», LA, a2v, 27.

«[...] y en confirmación deste parecer el maestro francisco sancho aprobándolo citó vn lugar de Aristótil en que dize que noes lo mismo ser contrario y ser differente.», FLC, fol. 216v, 39.

«El texto de los Evangelistas dize assí [continúa el relato evangélico]», LO, 341, 8.

«Item dizen maestro Romero, y maestro Diascórides, y maestro Iran, y maestro Macedo, y todos los otros maestros y sabios, que tomes los cabellos del hombre, y ponlos sobre las brasas $[\ldots] »$, TH, 5v, 27.

«Item dize Auicena, que tomes el estiércol del can y quema lo y dalo a beuer, y estancará.», TH, 30v, 4.

\section{RESUMEN Y CONCLUSIÓN}

En resumen, durante la segunda mitad del siglo XVI, el presente de indicativo, en relación con la temporalidad verbal, muestra unos usos directos e indirectos muy parecidos a los del español actual. Algunos usos indirectos, como la incorporación del presente en el futuro analítico, están en desuso, pero la mayoría continúan vigentes. Es resaltable la versatilidad del presente de indicativo, que es sin duda el tiempo con más capacidad de adaptación de toda la conjugación para situar la acción verbal en cualquier momento de la línea temporal y para integrarse en los principales tipos de secuencia textual (narrativa, expositiva e instruccional). Otros tiempos del modo indicativo no tienen tanta flexibilidad $^{38}$.

Para finalizar este trabajo de Pragmática Histórica, nos parece interesante exponer los usos directos en indirectos del presente de indicativo mediante un cuadro, por vectores temporales, en donde podemos comprobar qué casillas del sistema de la temporalidad del modo indicativo pueden ser ocupadas por el presente de indicativo y en cuáles no hemos atestiguado su presencia después de analizar todos los enunciados donde aparece el presente en nuestro corpus:

${ }^{38}$ Así lo constatamos en los capítulos 8.12 y 9 de nuestra tesis doctoral. 
USOS DIRECTOS E INDIRECTOS DEL PRESENTE DE INDICATIVO POR VECTORES TEMPORALES

\begin{tabular}{|c|c|c|c|}
\hline \multirow[b]{4}{*}{$\begin{array}{c}\text { TEMPORALIDAD } \\
\text { ABSOLUTA }\end{array}$} & \multicolumn{2}{|c|}{ VECTOR TEMPORAL } & Uso \\
\hline & \multicolumn{2}{|c|}{$-\mathrm{V}$} & Presente histórico \\
\hline & \multicolumn{2}{|c|}{$\mathrm{oV}$} & $\begin{array}{c}\text { Presente actual } \\
\text { Presente durativo }\end{array}$ \\
\hline & \multicolumn{2}{|c|}{$+\mathrm{V}$} & $\begin{array}{l}\text { Presente con valor de futuro: } \\
\text { futuro analítico; } \\
\text { con perífrasis; } \\
\text { sin perífrasis; } \\
\text { en oraciones condicionales }\end{array}$ \\
\hline \multirow{9}{*}{$\begin{array}{l}\text { TEMPORALIDAD } \\
\text { RELATIVA }^{39}\end{array}$} & \multirow{3}{*}{$(\mathrm{O}-\mathrm{V})$} & $-\mathrm{V}$ & $\varnothing$ \\
\hline & & $\mathrm{OV}$ & Presente con valor de imperfecto \\
\hline & & $+\mathrm{V}$ & $\varnothing$ \\
\hline & \multirow{3}{*}{$(\mathrm{OoV})$} & $-\mathrm{V}$ & $\begin{array}{c}\text { Presente con valor } \\
\text { de perfecto compuesto }\end{array}$ \\
\hline & & $\mathrm{OV}$ & $\varnothing$ \\
\hline & & $+\mathrm{V}$ & $\varnothing$ \\
\hline & \multirow{3}{*}{$(\mathrm{O}+\mathrm{V})$} & $-\mathrm{V}$ & $\varnothing$ \\
\hline & & $\mathrm{OV}$ & $\varnothing$ \\
\hline & & $+\mathrm{V}$ & $\varnothing$ \\
\hline \multirow[b]{2}{*}{ OTROS USOS } & \multicolumn{2}{|c|}{$\begin{array}{l}\text { VALOR DE } \\
\text { IMPERATIVO }\end{array}$} & $\begin{array}{c}\text { Presente con valor de } \\
\text { imperativo: } \\
\text { futuro analítico; } \\
\text { con perífrasis de infinitivo; } \\
\text { vamos }\end{array}$ \\
\hline & \multicolumn{2}{|c|}{$\begin{array}{l}\text { TEMPORALIDAD } \\
\text { PERMANENTE }\end{array}$} & $\begin{array}{c}\text { Presente habitual } \\
\text { Presente descriptivo } \\
\text { Presente de existencia } \\
\text { Presente hipotético / enfático } \\
\text { Presente para citas escritas } \\
\text { Presente permanente: } \\
\text { frases hechas; } \\
\text { refranes; } \\
\text { verdades eternas; } \\
\text { reflexiones morales; } \\
\text { definiciones; } \\
\text { verdades empíricas }\end{array}$ \\
\hline
\end{tabular}

CUADRO 3

${ }^{39} \mathrm{El}$ presente de indicativo solo tiene usos secundarios como tiempo relativo del primer nivel de relatividad. No hemos constatado ningún caso en el que asuma la temporalidad del condicional compuesto: ((O-V)+V)-V. Por otro lado, el único uso directo del presente es el que se corresponde al vector oV (temporalidad absoluta), es decir, los presentes llamados actual y durativo; el resto de los usos son indirectos. 


\section{BIBLIOGRAFÍA}

Aarts, J. y MeIss, W. (1984): Corpus linguistic, Amsterdam, Rodopi.

Alarcos Llorach, E. (1980): Gramática de la lengua española, Madrid, Espasa Calpe.

Alvar, Manuel y PotTIER, Bernard (1987): Morfología histórica del español, Madrid, Gredos.

Alvar EzQuerra, M. y CorPas PAStor, G. (1994): Estudios para un corpus del español, Málaga, Universidad de Málaga.

Barco Adalid, M. ${ }^{a}$ Teresa (2000): La Lingüística del Corpus: Creación de un corpus de textos turísticos, memoria de investigación dirigida por el Dr. D. F. Miguel Martínez Martín, Biblioteca Central de la UNED, sig. 2731.

BELLO, Andrés (1847): Gramática de la lengua castellana, Madrid, EDAF, 1984.

Bull, W. E. (1960): Time. Tense and the Verb. A Study in Theoretical Linguistics, whit Particular Attention to Spanish, Berkeley, University of California Press.

Comrie, Bernard (1985): Tense, Cambridge, Cambridge University Press.

Coseriu, E. (1977): Principios de semántica estructural, Madrid, Gredos.

CuAdRADO GómEZ, Carlos (2011): La temporalidad verbal en la segunda mitad del siglo XVI. Modo indicativo, UNED, Madrid, Biblioteca Central de la UNED, sign. TD04625.

EChenique Elizondo, M. ${ }^{a}$ Teresa y SÁnChez MÉndez, Juan (2005): Las lenguas de un reino. Historia de la Lingüística Hispánica, Madrid, Gredos.

EsCANDELl VidAL, M. ${ }^{a}$ Victoria (1993): Introducción a la Pragmática, Madrid, UNED-Anthropos.

FuENTES RodríGuez, Catalina (1996a): Aproximación a la estructura del texto, Málaga, Librería Ágora.

- (1996b): La sintaxis de los relacionantes supraoracionales, Madrid, Arco Libros.

- (1996c): Ejercicios de sintaxis supraoracional, Madrid, Arco Libros;

- (1999): La organización informativa del texto, Madrid, Arco Libros.

- (2000): Lingüística pragmática y análisis del discurso, Madrid, Arco Libros.

GARCÍA-MACHO, M. ${ }^{a}$ Lourdes y PenNy, Ralph (2001): Gramática histórica de la Lengua Española. Morfología, Madrid, UNED.

Gutiérrez Araus, M. ${ }^{a}$ Luz (1997): Formas del pasado en indicativo, Madrid, Arco Libros.

LAPESA, Rafael (1980): Historia de la Lengua Española, Madrid, Gredos.

- (2000): Morfosintaxis histórica del verbo español», en Rafael Lapesa, Estudios de morfosintaxis histórica del español, Vol. 2, edición de Rafael Cano Aguilar y M. ${ }^{a}$ Pilar Echenique Elizondo, Madrid, Gredos, pp. 730-885.

LAUSBERG, Heinrich (1966): Manual de retórica literaria, Vol. 2, Madrid, Gredos.

LóPEZ GARCíA, Ángel (1990): «La interpretación metalingüística de los tiempos, modos y aspectos del verbo español: ensayo de fundamentación», en I. Bosque (ed.), Tiempo y aspecto en español, Madrid, Cátedra, pp. 107-176.

Lyons, John (1997): Semántica lingüística. Una introducción, Barcelona, Paidós.

Pérez, M. ${ }^{a}$ Rosa (1998): El sistema verbal en Gonzalo de Berceo. Las formas de la irrealidad, Santiago de Compostela, Universidad de Santiago de Compostela.

PÉREZ SALDANYA, Manuel (2004): «Los tiempos verbales: dificultades teóricas y terminológicas», en L. García Fernández, ed. (2004): El pretérito imperfecto, Madrid, Gredos, p. 194-228.

PoRTo DaPena, José Álvaro (1989): Tiempos y formas no personales del verbo, Madrid, Arco Libros.

Real Academia Española (1973): Esbozo de una Nueva Gramática de la Lengua Española, Madrid, Espasa Calpe.

- (2009): «El verbo (I). Tiempo y aspecto léxico. Los tiempos del modo indicativo», en REAL ACADEMIA EsPañola, Nueva gramática de la lengua española, Madrid, Espasa Libros, pp. 16731795. 
ReICHENBACH, Hans (1947): Elements of Symbolic Logic, London, Colliers-Macmillan.

RoJo, Guillermo (1990): «Relaciones entre temporalidad y aspecto en el verbo español», en I. Bosque (ed.), Tiempo y aspecto en español, Madrid, Cátedra, pp. 17-45.

Rojo, Guillermo y VeIGA, Alexandre (1999): «El tiempo verbal. Los tiempos simples», en I. Bosque y V. Demonte (dirs.), Gramática descriptiva de la lengua española, Vol. 2, Madrid, Espasa Calpe, pp. 2867-2934.

Sastre RuAno, M. ${ }^{a}$ Ángeles (1995): El Indicativo, Salamanca, Ediciones Colegio de España. WeINRICH, H. (1974): Estructura y función de los tiempos en el lenguaje, Madrid, Gredos. 
